\title{
A FURTHER NOTE ON MONGOLISM IN TWINS
}

\author{
BY
}

\author{
ALWYN SMITH
}

From the Department of Medicine, University of Birmingham

\begin{abstract}
The discovery of an abnormality of the chromosomes of the cells of mongoloid defectives (Lejeune, Gautier, and Turpin, 1959a) and its later confirmation (Lejeune, Gautier and Turpin, 1959b; Jacobs, Baikie, Court Brown, and Strong, 1959) would seem to provide evidence that the causal mechanism of this condition operates at an early stage in the development of the affected individual. It now seems most likely that the condition is determined at or shortly after conception. In view of this evidence, it is surprising that examinations of concordance and zygotic type of affected twin pairs reported in the literature appear to show that the reported incidence of concordance is significantly less than that expected if monozygous pairs are invariably concordant.
\end{abstract}

The present author (Smith, 1955) and more recently Keay (1958) have examined series compiled from the literature and have considered the question in two ways:

(a) By comparing the proportion of concordant pairs with the expected proportion of monozygous pairs in a population of twin pairs born at maternal ages comparable with those at which mongols are usually born.

(b) By comparing the numbers of like and unlike sex pairs in pairs reported or presumed to be dizygous.

Both authors considered the possible effects of unrepresentativeness, and concluded that the data provided qualified support for the view that discordance might occur in monozygous pairs.

However, it has been suggested to the present author by Dr. Gordon Allen (personal communication) that it is fallacious to compare the observed frequency of concordance in affected pairs with the expected frequency of monozygous pairs in a population of unaffected pairs, if the hypothesis is to be tested that monozygous pairs are invariably concordant. Allen has advanced his reasons for this view elsewhere (Allen, 1955) and the argument relevant to the present discussion may be stated as follows:

In assuming for purposes of hypothesis that monozygous pairs are always concordantly affected and dizygous pairs usually although not invariably discordantly affected, we are assuming that the condition is determined at conception or at least before the stage at which a zygote splits to form a monozygous pair. Thus we are regarding the condition as being distributed not among twin pairs but among the zygotes that will ultimately present as twin pairs. A series of twin pairs ascertained by inclusion of pairs in which one or both members are affected will relate to two kinds of zygote; i.e. those who will subsequently split to form a monozygous twin pair and those who will simply be born in twos as dizygous twin pairs. If incidence is unrelated to zygotic type (and we have no reason to suppose that it is related), we should expect the proportion of affected and subsequently monozygous zygotes to approximate to the proportion of subsequently monozygous zygotes in the related population of unaffected twin zygotes.

Let the proportions of monozygous and dizygous twin pairs in a related population be $p: q$. Then the proportions of subsequently monozygous to subsequently dizygous zygotes will be $p: 2 q$.

In a series of affected twin pairs drawn from such a population by inclusion of pairs in which one or both members are affected, all monozygous pairs will be concordantly affected but dizygous pairs may be either concordantly or discordantly affected. If $m$ is the chance that a zygote may be affected and may introduce its pair to the series, the probability that any dizygous pair is concordantly affected is $\mathbf{m}^{2}$ and the probability that it is discordantly affected is $2 m(1-m)$. The probability that a monozygous pair is affected and included is $m$. If these probabilities are applied to the proportions of monozygous and dizygous pairs in the related population, the proportions in the series are given as:

$$
\begin{aligned}
& m p \text { monozygous (concordant) } \\
& 2 m(1-m) q \text { dizygous (discordant) } \\
& m^{2} q \text { dizygous (concordant) }
\end{aligned}
$$

Since in this case $m$ is small, $2 m(1-m) q$ approximates to $2 m q$ and $m^{2} q$ is negligibly small, so that the proportions of monozygous and dizygous affected pairs in the series will be $p: 2 q$, or similar to that of subsequently monozygous and subsequently 
dizygous zygotes in the related population and not to that of monozygous and dizygous pairs in the related population.

In view of the new data which have accumulated since the earlier papers (Smith, 1955; Keay, 1958) were published, it seemed desirable to re-examine the question of concordance and zygotic type in the light of Allen's comment.

To the data assembled by Keay, which included series compiled by Øster (1953) and Smith (1955), the present communication adds the reported pairs shown in Table I.

TABLE I

EIGHT PAIRS OF TWINS SUPPLEMENTARY TO THOSE ASSEMBLED BY KEAY (1958)

\begin{tabular}{|c|c|c|c|c|c|c|}
\hline \multicolumn{4}{|c|}{ Author } & \multirow[b]{2}{*}{$\begin{array}{l}\text { Date } \\
1957 \\
1957 \\
1957 \\
1957 \\
1957 \\
1957 \\
1957 \\
1958\end{array}$} & Sex* & $\begin{array}{c}\text { Zygotic Type } \\
\text { Unknown }\end{array}$ \\
\hline $\begin{array}{l}\text { Mistlin .. } \\
\text { Higgie .. } \\
\text { Ormiston } \\
\text { Guilbride } \\
\text { Lewis .. } \\
\text { Mark . } \\
\text { Anthony an } \\
\text { Murray . . }\end{array}$ & $\begin{array}{l}\ldots \\
\ldots \\
\ldots \\
\ldots \\
\ddot{H u g} \\
\ldots\end{array}$ & $\begin{array}{c}\ldots \\
\cdots \\
\cdots \\
\cdots \\
\text { rho } \\
\ldots\end{array}$ & $\begin{array}{l}\ldots \\
\cdots \\
\ldots \\
\ldots \\
\cdots \\
\text { s. } \\
\ldots\end{array}$ & & $\begin{array}{ll}\mathbf{F} & \mathbf{F} \\
\mathbf{M} & \mathbf{F} \\
\mathbf{M} & \mathbf{M} \\
\mathbf{F} & \mathbf{M} \\
\mathbf{M} & \mathbf{F} \\
\mathbf{F} & \mathbf{F} \\
\mathbf{F} & \mathbf{F} \\
\mathbf{F} & \mathbf{F}\end{array}$ & $\begin{array}{l}\text { Unknown } \\
\text { Dizygous } \\
\text { Unknown } \\
\text { Dizygous } \\
\text { Dizygous } \\
\text { Unknown } \\
\text { Unknown } \\
\text { Unknown }\end{array}$ \\
\hline
\end{tabular}

Some reports have been omitted where either the diagnosis or the recording of sex seems unreliable. The total relevant data are summarized in Table II.

TABLE II

DISTRIBUTION OF TWIN PAIRS, ASSUMING THAT ALL PAIRS DISCORDANT FOR MONGOLISM ARE DIZYGOUS AND THAT ALL CONCORDANT PAIRS OF UNDETERMINED ZYGOTIC TYPE ARE MONOZYGOUS

\begin{tabular}{|c|c|c|c|c|}
\hline \multicolumn{2}{|c|}{ Pairs } & Concordant & Discordant & Total \\
\hline Monozygous & .. & 25 & 0 & 25 \\
\hline \multirow{2}{*}{ Dizygous } & Like Sex.. & 1 & 76 & 77 \\
\hline & Unlike Sex & 1 & 67 & 68 \\
\hline Total & .. & 27 & 143 & 170 \\
\hline
\end{tabular}

In a previous communication (Smith, 1955), the expected proportion of monozygous pairs in a population of twin pairs born at the maternal age at which mongols are usually born was estimated as $26 \cdot 3$ per cent. This figure was derived from the maternal age distribution of 241 mongols born in Birmingham in the years 1942-1952 (Smith and Record, 1955) and the maternal age distribution of twins by zygotic type estimated by Weinberg's method from data published by the Registrar General. The expected proportion of zygotes resulting in monozygous twins is therefore $(26 \cdot 3 \div[147 \cdot 4+26 \cdot 3]) \times 100$ per cent. $=15 \cdot 1$ per cent.

Table II shows that, of the 170 pairs on record, 27 pairs are concordant, of which two pairs must be accepted as dizygous (MacKaye, 1936; Nicholson and Keay, 1957). If the remaining 25 pairs are assumed to be monozygous, they represent $14 \cdot 7$ per cent. of the total number of pairs. Thus agreement is good between the expected and observed proportions of monozygous pairs on the assumption that all concordant pairs not acceptable as dizygous are. in fact, monozygous.

If we assume all discordant pairs to be dizygous and add to their number the two concordant pairs acceptable as dizygous, the numbers of like sex (77) and unlike sex pairs (68) do not depart significantly from the expected equality.

Thus the evidence at present available supports the view that affected monozygous pairs are invariably concordant for mongolism and that affected dizygous pairs are usually, although not invariably, discordant. Such a view is most readily reconciled with the hypothesis that the condition is determined at or shortly after conception.

\section{SUMMARY}

Data on mongolism in twins assembled from the literature are used to re-examine the question whether the observed frequency of concordance is consistent with the view that monozygous pairs are always concordant for mongolism, and that dizygous pairs are usually, although not invariably, discordant. The observed proportion of concordant and not dizygous pairs is 14.7 per cent. compared with an expected proportion of monozygous pairs of $15 \cdot 1$ per cent.

The number of like and unlike sex pairs among pairs considered to be dizygous does not differ significantly from the expected equality.

The data provide support for the view that monozygous pairs are always concordant and dizygous pairs usually discordant, a view that is most readily interpreted as evidence that the condition is determined at or shortly after conception.

\section{REFERENCES}

Allen, G. (1955). Acta Genet. med. (Roma), 4, 143.

Anthony, D., and Thomas, J. G. Hugh. (1957). Brit. med. J., 2, 1546 Guilbride, A. H. H. (1957), Ibid., 2, 1368.

Higgie, E. J. (1957). Ibid., 2, 1240.

Jacobs, P. A., Baikie, A. G., Court Brown, W. M., and Strong, J. A. (1959). Lancet, 1, 710 .

Keay, A. J. (1958). J. ment. Defic. Res., 2, 1.

Lejeune, J., Gautier, M., and Turpin, R. (1959a). C. R. Acad. Sci. Paris, 248, 602 .

,, (1959b). Ibid., 248, 1721.

Lewis, J. (1957). Brit. med. J., $2,1368$.

MacKaye, L. (1936). Amer. J. Dis. Child., 52, 141

Mark, J. A. (1957), Brit. med. J., $2,1490$.

Mistlin, L. L. (1957). Ibid., 2, 1179 .

Murray, R. G. (1958). Ibid., 1, 103.

Nicholson, D. N., and Keay, A. J. (1957). Arch. Dis. Childh., 32, 325 Ormiston, G. (1957). Brit. med. J., 2, 1309.

Oster, J. (1953). "Mongolism: A Clinicogenealogical Investigation comprising 526 Mongols living on Seeland and Neighbouring Islands in Denmark." Danish Science Press, Copenhagen.

[Opera ex Domo Biologiae Hereditariae Humanae Universitatis Hafniensis, Vol. 32.]

Smith, A. (1955). Brit. J. prev. soc. Med., 9, 212

Smith, A. (1955), Brit. J. prev. soc. Med., 9, 212 